Dyadic Value Distance: Determinants and Consequences

Adrian Jäggi, Stefan Legge, Lukas Schmid

October 2017 Discussion Paper no. 2017-18

School of Economics and Political Science,

University of St. Gallen

Department of Economics 


$\begin{array}{ll}\text { Editor: } & \text { Vanessa Pischulti } \\ & \text { University of St.Gallen } \\ & \text { School of Economics and Political Science } \\ & \text { Department of Economics } \\ & \text { Müller-Friedberg-Strasse 6/8 } \\ & \text { CH-9000 St. Gallen } \\ & \text { Phone +41 71 224 23 07 } \\ & \text { Email seps@unisg.ch } \\ & \text { School of Economics and Political Science } \\ & \text { Department of Economics } \\ \text { Publisher: } & \text { University of St.Gallen } \\ & \text { Müller-Friedberg-Strasse 6/8 } \\ & \text { CH-9000 St. Gallen } \\ & \text { Phone +41 71 224 23 07 } \\ & \text { http://www.seps.unisg.ch }\end{array}$




\section{Dyadic Value Distance: Determinants and Consequences ${ }^{1}$}

Adrian Jäggi, Stefan Legge, Lukas Schmid

Author's adress:

Adrian Jäggi

Swiss Institute for International Economics and Applied

Economics Research (SIAW)

University of St.Gallen

Bodanstrasse 8

$\mathrm{CH}-9000$ St.Gallen

Phone +41712243159

Email_adrian.jaeggi@unisg.ch

Website www.siaw.unisg.ch

Stefan Legge, Ph.D.

Swiss Institute for International Economics and Applied

Economics Research (SIAW)

University of St.Gallen

Bodanstrasse 8

$\mathrm{CH}-9000$ St.Gallen

Phone +41712242338

Email_stefan.legge@unisg.ch

Website www.siaw.unisg.ch

Dr. Lukas Schmid

University of Lucerne

Faculty of Economics and Management

P.O. Box 4466

$\mathrm{CH}-6002$ Lucerne

Phone +41412295850

Email lukasdavid.schmid@unilu.ch

Website www.lukasschmid.net

\footnotetext{
${ }^{1}$ The data set on dyadic value distance is available to researchers and can be found on the authors' websites.
} 


\section{Abstract}

This paper establishes a measure of bilateral differences in values using 857 questions from the World Values Survey. We explore the determinants of value distance, linking it to geography as well as the historical relatedness of populations across 90 countries. Furthermore, we explore the explanatory power of value distance for the diffusion of technological development.

\section{Keywords}

Dyadic Value Distance, Genetic Distance, Income Differences

\section{JEL Classification}

J11, O33, O47, Z13 


\section{Introduction}

The recent literature in economics has provided mounting evidence that culture matters for economic outcomes (Guiso, Sapienza and Zingales, 2006; Alesina and Giuliano, 2015). While earlier research emphasized the role of cultural variables for economic outcomes within a country (Alesina and Giuliano, 2010; Eugster et al., 2011), a more recent literature has put forward the impact of bilateral cultural differences between countries as a determinant of several economic outcomes, including technology diffusion (Spolaore and Wacziarg, 2009), fertility choice (Spolaore and Wacziarg, 2016a), conflict (Spolaore and Wacziarg, 2016b), and trade (Fensore, Legge and Schmid, 2017). An important channel through which cultural differences affect economic and social relationships is the degree to which values differ between two populations. Yet there is no comprehensive measure of such bilateral differences.

This paper intents to fill this gap by using the World Values Survey (WVS) to establish the dyadic value distance (DVD) as a measure of bilateral differences in values. We demonstrate that DVD is closely associated with geographic distance as well as with genetic distance, a commonly used measure for the historical relatedness of populations across the globe. In addition, we apply our measure of value distance to a specific research question and test how much of the diffusion of technology can be accounted for by differences in values. This builds upon Spolaore and Wacziarg (2009) who argue that genetic distance captures differences in values, norms, and habits and thus has affected the historical spread of technology.

Our work is related to Becker, Enke and Falk (2017) who document that specific values, such as risk aversion, altruism, reciprocity, and trust, are related to a population's ancestry. Dohmen, Falk and Huffman (2016) find that patience matters for the accumulation of physical and human capital and thus crucially affects variation in economic development between countries. We complement this evidence by documenting that other dimensions of value differences help explain the variation in GDP per capita across countries, most prominently a society's openness to new ideas and immigration, the attitude towards freedom versus equality, as well as work ethics. More broadly, our work adds to the literature on the importance of values and norms for a variety of social and economic outcomes, including smoking behavior, educational choices, and political preferences (Alesina and Giuliano, 2014; Galor and Özak, 2016). 


\section{Data}

The data set that we use in this study is based on three sources: the World Values Survey (WVS), information on bilateral genetic distance, and numerous country-specific and bilateral variables. The latter two sources are relevant for the analysis of determinants and consequences of value differences. To measure differences in values, we use the longitudinal data set of the World Values Survey. This data set includes answers from all six waves that were conducted between 1981 and 2014. In total, representative national surveys were conducted in 95 countries although not all countries were included in each wave. Our analysis is based on a total of 857 questions. In addition, we provide value differences in 19 categories that we will describe later. ${ }^{1}$

We complement our dataset with data on genetic distances from Spolaore and Wacziarg (2017) who argue that genetic distance is a measure of ancestral distance that captures a multitude of characteristics including differences in habits, customs, beliefs, norms, and conventions. One can consider genetic distance as a summary statistic for intergenerationally transmitted traits across populations. The study by Spolaore and Wacziarg (2015) confirms this intuition by showing that although measures of cultural distance are poorly correlated to one-another, genetic distance is positively correlated to all of them. The data on genetic distance provided by Spolaore and Wacziarg (2017) is based on 267 populations defined by Pemberton, DeGiorgio and Rosenberg (2013) as well as ethnic compositions compiled by Alesina et al. (2003). While all people in the world share the same gene variants (alleles), the frequencies differ across populations. When populations split apart, genes start to change due to random drift or natural selection. Assuming drifts are constant, measured genetic distance can be thought of as a molecular clock. In other words, genetic distance provides us with an approximate time since the populations of two countries were the same population.

Finally, we enrich our data set with detailed economic and geographic information at the country-level. This includes data on GDP and population size for each country. As primary source, we use the Penn World Table 9.0 (PWT), for which we take into account the most

\footnotetext{
${ }^{1}$ In the Appendix, we provide an overview of the country coverage for each wave in Table A.1. Furthermore, Table A.2 provides detailed information on which questions we use for each category. We also indicate the coverage of the survey for each question.
} 
recent update by Feenstra, Inklaar and Timmer (2015). ${ }^{2}$ We also add geographic information to our data set from CEPII's data. This comprises both information for each country as well as bilateral variables. The former includes each country's location in terms of latitude and longitude, island status, as well as a dummy for being landlocked. The bilateral variables provide information on contingency as well as access to the same sea. Overall, we have 90 countries in our data set. Hence, there are $(90 \times 89) / 2=4,005$ bilateral observations. ${ }^{3}$

\section{Dyadic Value Distance}

Drawing on answers to the World Values Survey (WVS), we develop a measure of bilateral value distance. We build upon Desmet et al. (2011) and compute the average Manhattan distance in answers of the World Value Survey between countries. Hence, we measure the distance for a set of two countries $i$ and $j$ for a given question $x$ by

$$
w_{i, j, x}=\sum_{s=1}^{q}\left|x_{i}^{s}-x_{j}^{s}\right|
$$

where $x^{s}$ is the share of people choosing answer option $s$ to question $x$, such that $\sum_{s=1}^{q} x_{i}^{s}=1$ when $q$ denotes the number of possible answers. Using this metric, we take into account the structure of each question. To obtain a dyadic measure of differences in values, we aggregate the measure in equation (1) over all $N$ questions in the WVS to get

$$
w_{i, j}=\frac{1}{N} \sum_{x=1}^{N} w_{i, j, x}
$$

as the average absolute distance in values. When exploring the effect of ancestry on income levels, Spolaore and Wacziarg (2017) argue that the relative genetic distance to the technological frontier, the United States, rather than the bilateral distance affects technological differences. Therefore, we compute the relative distance in values to the United States between

\footnotetext{
${ }^{2}$ Note that the PWT database does not cover Lybia. Thus, we use the World Development Indicators as secondary data source to predict the missing GDP. This procedure insures that the GDP (per capita) values comparable even if they stem from different sources.

${ }^{3}$ We provide descriptive statistics on the data set in Table A.3 in the Appendix. Note that data on genetic distance is missing for Andorra, Puerto Rico, Tanzania, Yemen, as well as former Yugoslavia.
} 
two countries as

$$
r_{i, j, x}=\left|w_{i, U S, x}-w_{j, U S, x}\right|
$$

for each question $x$. Again, we can aggregate to have an overall measure of value distance for each country pair to obtain

$$
r_{i, j}=\frac{1}{N} \sum_{x=1}^{N} r_{i, j, x}
$$

which denotes the relative value distance to the United States between countries $i$ and $j$. The proposed measure avoids that the direct bilateral and the relative distances coincide, except for some special cases such as for questions with binary answer options and where $x_{U S}^{1}$ is larger or smaller than both $x_{i}^{1}$ and $x_{j}^{1}$. In this case, $w_{i, j, x}$ and $r_{i, j, x}$ are the same. ${ }^{4}$

- Figure 1 about here -

The dyadic value distances in our dataset appear to follow closely a normal distribution as documented in Figure 1. The largest distance is between El Salvador and Sweden with a value of 0.210 , the smallest is between Belarus and Ukraine with a value of 0.038 . To illustrate dyadic value distances for a single country, let us consider the United States for which we depict the bilateral distance to each country in Figure A.1 in the Appendix. The data shows that in terms of values, the United States is closest to Canada (distance of 0.054) and Australia (0.060), while Morocco (0.149) and Egypt (0.151) are most distant. The map in Figure A.1 in the Appendix hints at two hypothesis on the determinants of value differences. First, countries that are geographically close have, on average, smaller differences in values. Second, the historical relatedness of populations matters for how different values are between current nations. We explore both hypotheses in the next section in the context of our full dataset.

\section{Determinants of Dyadic Value Distance}

The literature in economics has defined culture as a set of beliefs and values that ethnic, religious, and social groups transmit from generation to generation (Guiso, Sapienza and Zingales,

\footnotetext{
${ }^{4}$ Our main variables of interest are the two value distance measures $\left(w_{i, j}\right.$ and $\left.r_{i, j}\right)$ using all available questions from the WVS. We also construct some value distance measures only including questions relating to some specific value (trust, for example). Table A.2 in the Appendix presents these categories, along with the WVS questions used to construct them.
} 
2006). We understand our measure of dyadic value distances as an integral part of cultural differences. Hence, we want to understand the origins of these differences by exploring two important determinants, namely geography and ancestral distance. The geographic distance between two countries is likely to affect value differences in at least two ways. First, migration between geographically close countries is very likely and thus changes a population's composition. This compositional change directly reduces value differences between countries with high migration flows. Second, geographically close countries are more likely to socially and economically interact with each other. These interactions in turn might translate into a convergence of values between countries. Panel (a) in Figure 2 lends support to the conjecture that geographic and dyadic value distance are positively related.

- Figure 2 about here -

A second potential determinant of value differences is ancestral distance, a measure that captures the relatedness of populations. As values are transmitted from generation to generation, we expect that countries that share more recent common ancestors are more likely to have smaller differences in values. Panel (b) of Figure 2 provides evidence for this hypothesis by depicting that countries with a larger ancestral distance also have a larger discrepancy in answers to the WVS. This relationship is robust to including fixed effects for countries in the regression equation. To further explore the factors that explain differences in values, Table 1 shows the result of six regressions. We find that genetic distance has a positive and highly significant effect on dyadic value distance, even when controlling for a large set of geographic variables. A one standard deviation increase in genetic distance raises differences in values by $11 \%$ of a standard deviation.

- Table 1 about here -

\section{Consequences of Dyadic Value Distance}

The previous section has documented that values are closely related to geographic and ancestral distance. Yet, what are the consequences of value differences between countries? In what 
follows, we provide evidence that dyadic value distance affects economic development. Previous research by Spolaore and Wacziarg (2009) shows that the diffusion of technology has been shaped by the relatedness of populations. Countries with a larger relative ancestral distance to the technological frontier (i.e., the United States) face higher obstacles in learning and adopting new technologies. Hence, their GDP per capita today is lower compared to nations whose populations are more closely related to the United States.

Interpreting their results, Spolaore and Wacziarg (2009) point out that genetic distance - a proxy for ancestral relatedness — serves as a summary statistic for the divergence in implicit beliefs, customs, habits, biases, or conventions. They note that studying the specific microeconomic mechanisms through which the effects operate is left for future research. ${ }^{5}$ To explore whether value differences help explain differences in current income levels, we introduce our measure of value distance into a gravity model that mimics the specification of Spolaore and Wacziarg (2009):

$$
\Delta Y_{i, j}=\beta_{1} D V D_{i, j}+\beta_{2} G D_{i, j}+\mathbf{X}_{i, j} \boldsymbol{\beta}+\varepsilon_{i, j}
$$

where the left-hand side, $\Delta Y_{i, j}=\left|Y_{i}-Y_{j}\right|$, denotes the absolute difference in log GDP per capita between country $i$ and $j$ in the year 2000. Our focus is on the estimated parameters $\hat{\beta}_{1}$ and $\hat{\beta}_{2}$ which indicate the effect of dyadic value distance and genetic distance, respectively. Note that we can use either the simple distance between $i$ and $j$ or the relative distance to the United States. Furthermore, we add a vector of control variables denoted by $\mathbf{X}_{i, j}$ which includes geographic distance, common border, differences in latitude and longitude, access to the same sea, as well as dummy variables for island and landlocked status. We follow Cameron, Gelbach and Miller (2011) as well as Egger and Tarlea (2015) and cluster the standard error $\left(\varepsilon_{i, j}\right)$ at the country-pair level.

— Table 2 about here -

The results of Table 2 show that both genetic distance and our measure of value distance

\footnotetext{
5" What traits are captured by genetic distance? We argue that, by its very definition, genetic distance is an excellent summary statistic capturing divergence in the whole set of implicit beliefs, customs, habits, biases, conventions, etc. that are transmitted across generations - biologically and/or culturally — with high persistence." (Spolaore and Wacziarg, 2009, p.471).
} 
have a significant impact on bilateral income differences. Column (1) documents that increasing the relative value distance raises the gap in current income levels. This effect is slightly smaller in column (2) when controlling for genetic distance to the United States as suggested by Spolaore and Wacziarg (2009). Notably, the coefficient of determination $\left(R^{2}\right)$ increases by about 30 percent. These results suggest two main conclusions: first, our measure of value distance has a large explanatory power for differences in GDP per capita around the world. Second, genetic distance appears to be a much more comprehensive measure, capturing substantially more than value differences that can be measured using the World Values Survey data. To illustrate the magnitude of the coefficients, we report the standardized beta coefficients. These are defined as the effect of a one-standard-deviation change in the regressor, expressed as a percentage of one standard deviation of the dependent variable. For the relative value distance, we obtain a standardized beta of about $23.7 \%$. In comparison, we find a similar standardized beta of $24.6 \%$ for the relative genetic distance. These estimates are comparable in magnitude to the impact of linguistic and religious distance for which Spolaore and Wacziarg (2009) find a standardized beta of $15.1 \%$ and $20.2 \%$, respectively. Using simple bilateral value distance as well as simple genetic distance, the results of columns (3) and (4) are consistent with our findings on relative distances. To explore which specific values affect the diffusion of technology, we use our bilateral measures on specific value distances.

- Figure 3 about here -

Figure 3 shows that values such as openness to new ideas and migration play a key role in the diffusion of technology. Notably, the finding with respect to migration is in line with prior research by Kerr (2008) who documents that technological knowledge can spread through migrants with a similar ethnic and cultural background. Furthermore, the relative valuation of freedom and equality as well as fate versus control are decisive values. 


\section{Conclusion}

This paper establishes a measure of dyadic value distance. We explore the determinants and consequences of value distances by linking it to geographic and ancestral relatedness across the world. The findings shed light on the spread as well as persistence of values across generations and space. In an application to Spolaore and Wacziarg (2009), we find that our measure can improve our understanding of the global diffusion of economic development. 


\section{References}

Alesina, Alberto, and Paola Giuliano. 2010. "The power of the family." Journal of Economic Growth, 15(2): $93-125$.

Alesina, Alberto, and Paola Giuliano. 2014. Family Ties. Vol. 2, Elsevier B.V.

Alesina, Alberto, and Paola Giuliano. 2015. "Culture and Institutions." Journal of Economic Literature, 53(4): 898-944.

Alesina, Alberto, Arnaud Devleeschauwer, William Easterly, Sergio Kurlat, and Romain Wacziarg. 2003. "Fractionalization." Journal of Economic Growth, 8(2): 155-194.

Becker, Anke, Benjamin Enke, and Armin Falk. 2017. "Ancient Origins of the Global Variation in Economic Preferences."

Cameron, A. Colin, Jonah B. Gelbach, and Douglas L. Miller. 2011. "Robust Inference With Multiway Clustering." Journal of Business \& Economic Statistics, 29(2): 238-249.

Desmet, Klaus, Michel Le Breton, Ignacio Ortuño-Ortín, and Shlomo Weber. 2011. "The stability and breakup of nations: A quantitative analysis." Journal of Economic Growth, 16(3): 183-213.

Dohmen, Thomas, Armin Falk, and David Huffman. 2016. "Patience and The Wealth of Nations."

Egger, Peter H., and Filip Tarlea. 2015. "Multi-way clustering estimation of standard errors in gravity models." Economics Letters, 134: 144-147.

Eugster, Beatrix, Rafael Lalive, Andreas Steinhauer, and Josef Zweimüller. 2011. "The Demand for Social Insurance: Does Culture Matter?" Economic Journal, 121(556): 413-448.

Feenstra, Robert C., Robert Inklaar, and Marcel P. Timmer. 2015. "The Next Generation of the Penn World Table." American Economic Review, 105(10): 3150-3182.

Fensore, Irene, Stefan Legge, and Lukas Schmid. 2017. "Human Barriers to Trade." St.Gallen Discussion Paper No. 2017-12.

Galor, Oded, and Ömer Özak. 2016. "The Agricultural Origins of Time Preference." American Economic Review, 106(10): 3064-3103.

Guiso, Luigi, Paola Sapienza, and Luigi Zingales. 2006. "Does Culture Affect Economic Outcomes?" Journal of Economic Perspectives, 20(2): 23-48.

Kerr, William R. 2008. "Ethnic Scientific Communities and International Technology Diffusion." The Review of Economics and Statistics, 90(3): 518-537.

Mayer, Thierry, and Soledad Zignago. 2011. "Notes on CEPII's distances measures: The GeoDist database." CEPII Working Paper 2011-25.

Pemberton, Trevor J., Michael DeGiorgio, and Noah A. Rosenberg. 2013. "Population structure in a comprehensive genomic data set on human microsatellite variation." G3 (Bethesda), 3(5): 903-919.

Spolaore, Enrico, and Romain Wacziarg. 2009. "The Diffusion of Development." Quarterly Journal of Economics, 124(2): 469-529.

Spolaore, Enrico, and Romain Wacziarg. 2015. "Ancestry, Language and Culture." In The Palgrave Handbook of Economics and Language., ed. Victor Ginsburgh and Shlomo Weber, Chapter 7. London:Palgrave Macmillan.

Spolaore, Enrico, and Romain Wacziarg. 2016a. "Fertility and Modernity." Tufts University Discussion Papers Series 07r9.

Spolaore, Enrico, and Romain Wacziarg. 2016b. "War and Relatedness." Review of Economics and Statistics, forthcoming.

Spolaore, Enrico, and Romain Wacziarg. 2017. "Ancestry and Development: New Evidence."

World Values Survey Association. 2015. "World Values Survey 1981-2014 v.20150418." 
Figure 1: Distribution of Simple Dyadic Value Distance

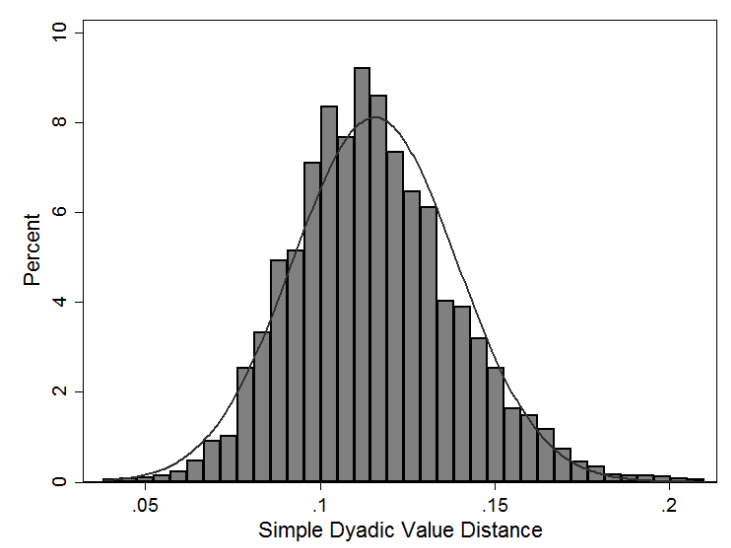

Note: The figure plots the distribution of the mean simple bilateral distances in answers to the World Value Surveys. A normal distribution is added to the figure.

Figure 2: Dyadic Values Distance and Geographic as well as Genetic Distance

(a) Geographic Distance

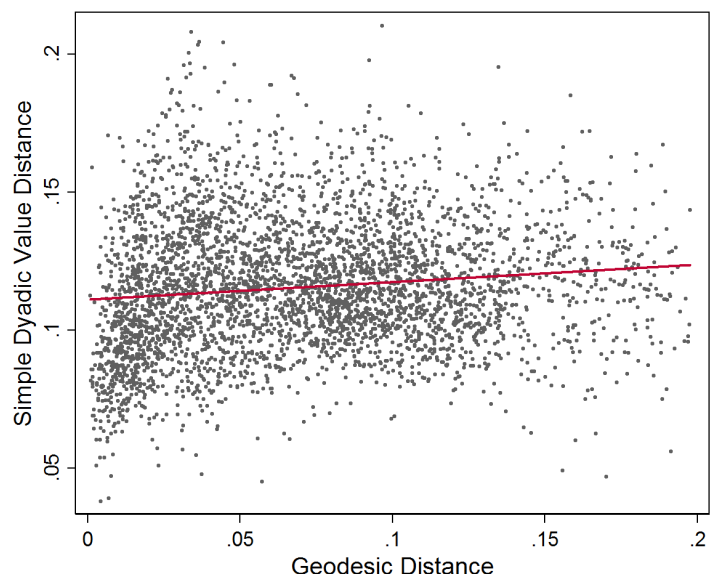

(b) Ancestral Distance

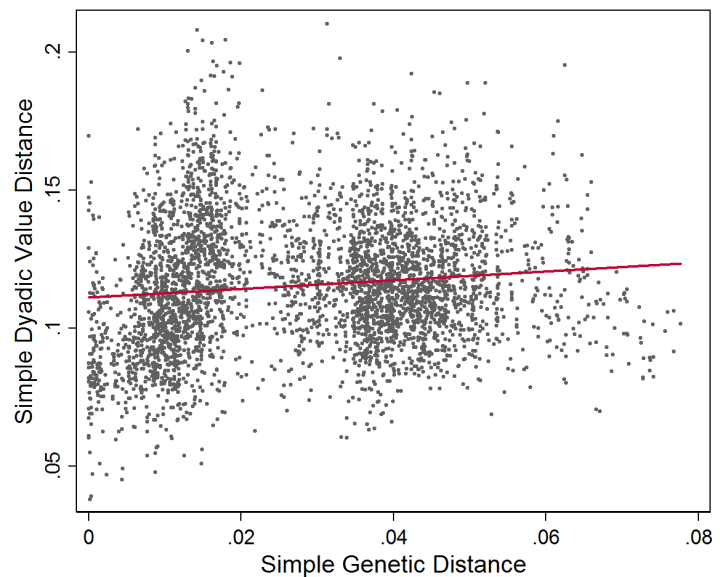

Note: The figure in part (a) plots the relationship between differences in values and geographic distance. Part (b) shows the relationship between differences in values and ancestral distance. Each dot reflects one country pair and a linear fit is added. Both relationships are highly statistically significant. 
Figure 3: Differences in GDP p.c. and Components of Dyadic Value Distance

(a) Simple Dyadic Value Distance

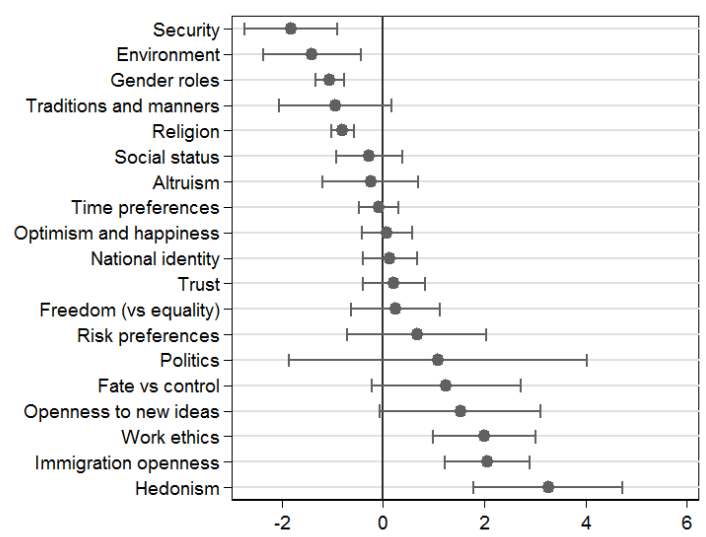

(b) Relative Dyadic Value Distance

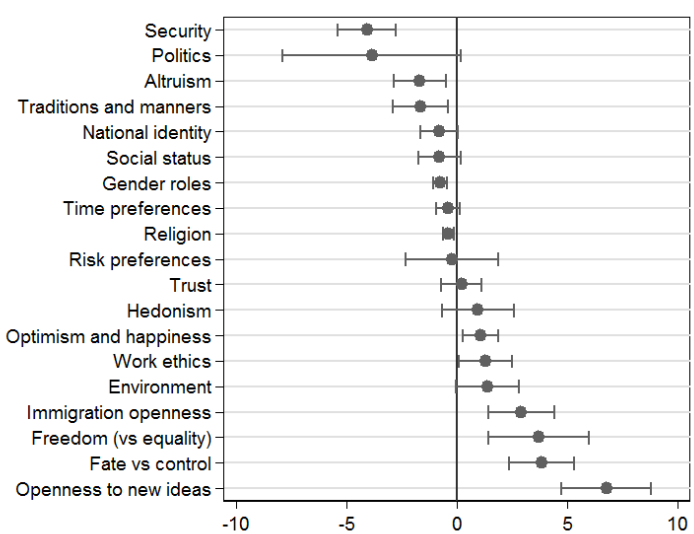

Note: The figure plots the estimated coefficients and their $95 \%$ confidence interval for the constructed variables listed in Table A.2, derived from re-estimating models (2) and (4) of Table 2 including these variables as additional regressors. The figure shows which WVS differences components can explain differences in GDP per capita, given genetic distance and the mean in WVS differences over all components. The components are further described in Table A.2. Panel (a) shows results for the simple differences in WVS, while panel (b) shows the results for the relative differences in WVS. 
Table 1: Determinants of Dyadic Value Distance

\begin{tabular}{|c|c|c|c|c|c|c|}
\hline \multirow[t]{3}{*}{ Dependent Variable: } & \multicolumn{6}{|c|}{ Dyadic Value Distance } \\
\hline & \multicolumn{3}{|c|}{ Relative Distance } & \multicolumn{3}{|c|}{ Simple Distance } \\
\hline & $(1)$ & $(2)$ & (3) & (4) & $(5)$ & $(6)$ \\
\hline Relative Genetic Distance & $\begin{array}{c}0.09 * * * \\
(0.02)\end{array}$ & & $\begin{array}{c}0.04^{* *} \\
(0.02)\end{array}$ & & & \\
\hline Simple Genetic Distance & & & & $\begin{array}{c}0.16^{* * *} \\
(0.02)\end{array}$ & & $\begin{array}{c}0.11^{* * *} \\
(0.03)\end{array}$ \\
\hline Geodesic Distance & & $\begin{array}{c}-0.04^{* * *} \\
(0.01)\end{array}$ & $\begin{array}{c}-0.05^{* * *} \\
(0.01)\end{array}$ & & $\begin{array}{c}-0.03 \\
(0.02)\end{array}$ & $\begin{array}{c}-0.07^{* * *} \\
(0.02)\end{array}$ \\
\hline Common Border & & $\begin{array}{c}-0.01^{* * *} \\
(0.00)\end{array}$ & $\begin{array}{c}-0.01^{* * *} \\
(0.00)\end{array}$ & & $\begin{array}{c}-0.03^{* * *} \\
(0.00)\end{array}$ & $\begin{array}{c}-0.03^{* * *} \\
(0.00)\end{array}$ \\
\hline Add. Geographic Controls & No & Yes & Yes & No & Yes & Yes \\
\hline Observations & 3,916 & 3,916 & 3,916 & 4,005 & 4,005 & 4,005 \\
\hline$R^{2}$ & 0.006 & 0.070 & 0.071 & 0.013 & 0.071 & 0.075 \\
\hline
\end{tabular}

Note: The table shows the result of six separate regressions using dependent variables as indicated in the top row. The sample includes all 90 countries. Geodesic Distance is re-scaled, measured in 100 '000 $\mathrm{km}$ to improve readability. The additional controls include differences in latitude and longitude, as well as dummies for being an island, landlocked and having access to the same sea. Standard errors are clustered at the country pair level and shown in parentheses. Significance at the $10 \%$ level is indicated by $*$, at the $5 \%$ level by $* *$, and at the $1 \%$ level by ***.

Table 2: Regression Results

\begin{tabular}{|c|c|c|c|c|}
\hline \multirow[t]{2}{*}{ Dependent Variable: } & \multicolumn{4}{|c|}{ Difference in per capita GDP } \\
\hline & (1) & $(2)$ & (3) & $(4)$ \\
\hline Relative Dyadic Value Distance & $\begin{array}{c}16.84^{* * *} \\
(0.99)\end{array}$ & $\begin{array}{c}16.26^{* * * *} \\
(0.96)\end{array}$ & & \\
\hline Relative Genetic Distance & & $\begin{array}{c}19.58^{* * *} \\
(1.25)\end{array}$ & & \\
\hline Simple Dyadic Value Distance & & & $\begin{array}{c}12.06^{* * *} \\
(0.52)\end{array}$ & $\begin{array}{c}11.35^{* * *} \\
(0.50)\end{array}$ \\
\hline Simple Genetic Distance & & & & $\begin{array}{c}16.86^{* * *} \\
(0.81)\end{array}$ \\
\hline Geographic Controls & Yes & Yes & Yes & Yes \\
\hline $\begin{array}{l}\text { Observations } \\
R^{2}\end{array}$ & $\begin{array}{l}3,916 \\
0.169\end{array}$ & $\begin{array}{l}3,916 \\
0.220\end{array}$ & $\begin{array}{l}4,005 \\
0.209\end{array}$ & $\begin{array}{l}4,005 \\
0.281\end{array}$ \\
\hline
\end{tabular}

Note: The table shows the result of four separate regressions using the absolute value of the difference in log GDP per capita between two countries as dependent variable. The sample includes all 90 countries for which we have data on genetic distance. Control variables include differences in latitude and longitude, geodesic distance as well as dummies for being an island, landlocked, sharing a common border and having access to the same sea. Standard errors are clustered at the country pair level and shown in parentheses. Significance at the $10 \%$ level is indicated by ${ }^{*}$, at the $5 \%$ level by ${ }^{* *}$, and at the $1 \%$ level by $* * *$. 


\section{Appendix}

\section{Appendix A: Additional Figures and Tables}

Figure A.1: Dyadic Value Distance for the United States

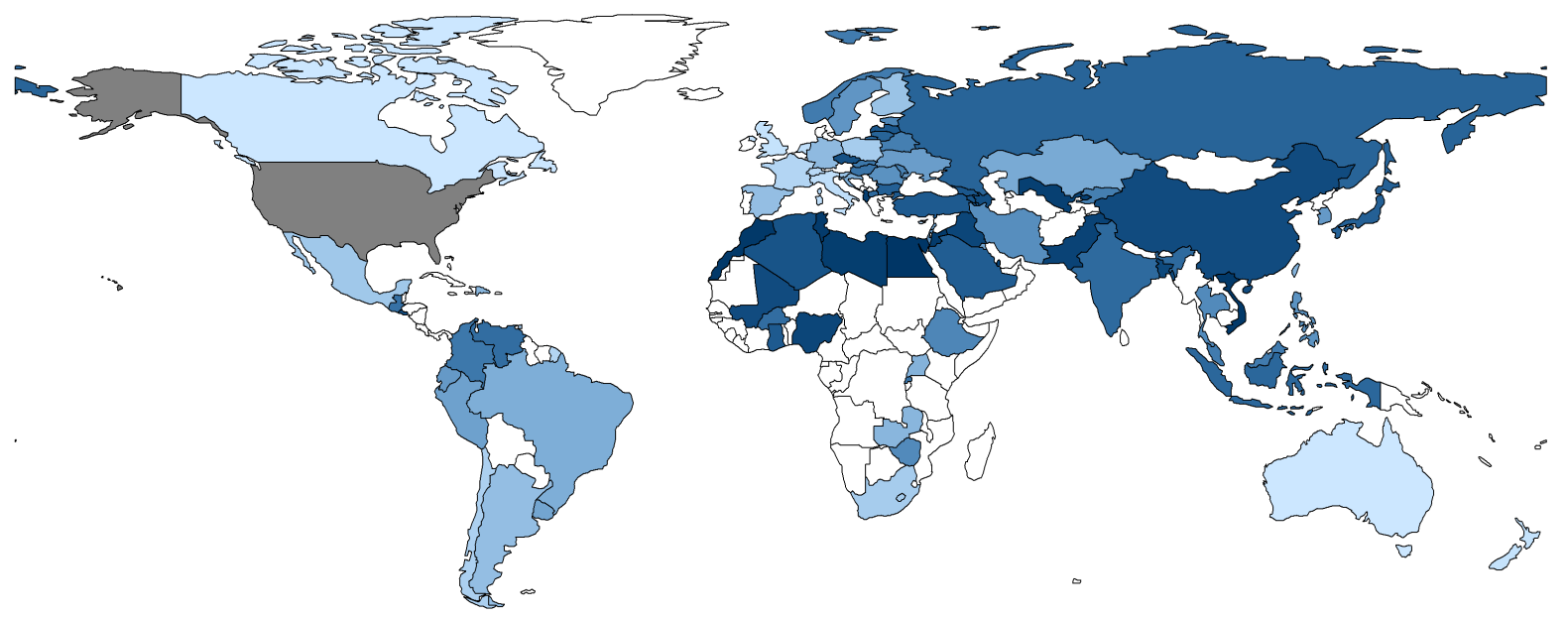

Note: The figure shows the dyadic value distance of the United States to 89 other nations. Countries for which there is no data available are left white. Brighter (darker) colors indicate smaller (higher) distances in values. 
Table A.1: Countries in the Sample and Coverage in WVS

\begin{tabular}{|c|c|c|c|c|c|}
\hline Country & WVS Waves & Country & WVS Waves & Country & WVS Waves \\
\hline Albania & 3,4 & Algeria & 4,6 & Argentina & $1,2,3,4,5,6$ \\
\hline Armenia & 3,6 & Australia & $1,3,5,6$ & Azerbaijan & 3,6 \\
\hline Bahrain & 6 & Bangladesh & 3,4 & Belarus & $2,3,6$ \\
\hline Brazil & $2,5,6$ & Bulgaria & 3,5 & Burkina Faso & 5 \\
\hline Canada & 4,5 & Chile & $2,3,4,5,6$ & China & $2,3,4,5,6$ \\
\hline Colombia & $3,5,6$ & Croatia & 3 & Cyprus & 5,6 \\
\hline Czech Republic & 2,3 & Dominican Republic & 3 & Ecuador & 6 \\
\hline Egypt & $4,5,6$ & El Salvador & 3 & Estonia & 3,6 \\
\hline Ethiopia & 5 & Finland & $1,3,5$ & France & 5 \\
\hline Georgia & $3,5,6$ & Germany & $3,5,6$ & Ghana & 5,6 \\
\hline Guatemala & 5 & Hong Kong & 5,6 & Hungary & $1,3,5$ \\
\hline India & $2,3,4,5,6$ & Indonesia & 4,5 & Iran & 4,5 \\
\hline Iraq & $4,5,6$ & Israel & 4,6 & Italy & 5 \\
\hline Japan & $1,2,3,4,5,6$ & Jordan & $4,5,6$ & Kazakhstan & 6 \\
\hline Korea & $1,2,3,4,5,6$ & Kuwait & 6 & Kyrgyzstan & 4,6 \\
\hline Latvia & 3 & Lebanon & 6 & Libya & 6 \\
\hline Lithuania & 3 & Macedonia & 3,4 & Malaysia & 5,6 \\
\hline Mali & 5 & Mexico & $1,2,3,4,5,6$ & Moldova & $3,4,5$ \\
\hline Morocco & $4,5,6$ & Netherlands & 5,6 & New Zealand & $3,5,6$ \\
\hline Nigeria & $2,3,4,6$ & Norway & 3,5 & Pakistan & $3,4,6$ \\
\hline Peru & $3,4,5,6$ & Philippines & $3,4,6$ & Poland & $2,3,5,6$ \\
\hline Qatar & 6 & Romania & $3,5,6$ & Russian Federation & $2,3,5,6$ \\
\hline Rwanda & 5,6 & Saudi Arabia & 4 & Singapore & 4,6 \\
\hline Slovakia & 2,3 & Slovenia & $3,5,6$ & South Africa & $1,2,3,4,5,6$ \\
\hline Spain & $2,3,4,5,6$ & Sweden & $3,5,6$ & Switzerland & $2,3,5$ \\
\hline Taiwan & $3,5,6$ & Thailand & 5,6 & Trinidad and Tobago & 5,6 \\
\hline Tunisia & 6 & Turkey & $2,3,4,5,6$ & U.S.A & $3,4,5,6$ \\
\hline Uganda & 4 & Ukraine & $3,5,6$ & United Kingdom & 3,5 \\
\hline Uruguay & $3,5,6$ & Uzbekistan & 6 & Venezuela & 3,4 \\
\hline Vietnam & 4,5 & Zambia & 5 & Zimbabwe & 4,6 \\
\hline
\end{tabular}

Note: The table shows the set of 90 countries which participated in at least one wave of the World Values Survey (WVS). We indicate in which waves each country participated. There were a total of six waves between 1981 and 2015.

Table A.2: Categories of WVS Questions

\begin{tabular}{lccc}
\hline \multicolumn{1}{c}{ Category } & Questions & Waves & \# Countries \\
\hline Trust & A165, D001, D001_B & $1,2,3,4,5,6$ & 90 \\
Time preferences & A038 & $1,2,3,4,5,6$ & 90 \\
Work ethics & A005, A030, C038, C039, C040, E040 & $1,2,3,4,5,6$ & 90 \\
Traditions and manners & A196, A198, B016 & $3,5,6$ & 86 \\
Immigration openness & C002, E143, G032 & $2,3,4,5,6$ & 85 \\
Openness to new ideas & A189 & 5,6 & 75 \\
Social status & A190, A194, C011, C014 & $1,2,3,4,5,6$ & 87 \\
Altruism & A193, A199, E129, E129C & $4,5,6$ & 81 \\
Risk preferences & A195 & 5,6 & 75 \\
Freedom (vs equality) & E010, E032, E035 & $2,3,4,5,6$ & 90 \\
\hline Security & A191, H001 & 5,6 & 75 \\
Hedonism & A003, A192 & $2,3,4,5,6$ & 90 \\
Optimism and happiness & A170, B017 & $1,2,3,4,5,6$ & 90 \\
Politics & E039 & $2,3,4,5,6$ & 89 \\
National identity & E012, G006 & $1,2,3,4,5,6$ & 90 \\
Religion & F050 & $1,2,3,4,6$ & 77 \\
Fate vs control & F198 & 5 & 47 \\
Gender roles & C001 & $2,3,4,5,6$ & 90 \\
Environment & A197, B008 & $3,4,5,6$ & 90 \\
\hline
\end{tabular}

Note: The table shows the 19 categories of questions based on the World Values Survey (WVS). Columns 3 and 4 indicate in which waves and in how many countries each question was included in the survey. 
Table A.3: Descriptive Statistics

\begin{tabular}{lccccc}
\hline \multicolumn{1}{c}{ Variable } & Mean & Std. Dev. & Min. & Max. & N \\
\hline Part I: Cultural Distance Variables: & & & & & \\
Simple Dyadic Value Distance & 0.12 & 0.02 & 0.04 & 0.21 & 4,005 \\
Relative Dyadic Value Distance & 0.07 & 0.01 & 0.03 & 0.11 & 3,916 \\
Simple Genetic Distance & 0.03 & 0.02 & 0.00 & 0.08 & 4,005 \\
Relative Genetic Distance & 0.01 & 0.01 & 0.00 & 0.04 & 4,005 \\
& & & & & \\
Part II: Country-Level Variables: & & & & & \\
GDP (billion USD) & & & & & \\
Population (milions) & 950.98 & $2,221.65$ & 14.18 & $15,273.33$ & 90 \\
GDP per capita (thousand USD) & 67.59 & 193.09 & 0.83 & $1,340.97$ & 90 \\
& 21.73 & 21.27 & 1.09 & 148.52 & 90 \\
Part III: Bilateral Variables: & & & & & \\
Geodesic Distance (in 1000 km) & & & & & \\
Common Border & 7.04 & 4.54 & 0.08 & 19.77 & 4,005 \\
Landlocked (none, one, both) & 0.03 & 0.16 & 0.00 & 1.00 & 4,005 \\
Access to Same Sea & 0.42 & 0.57 & 0.00 & 2.00 & 4,005 \\
Island (none, one, both) & 0.14 & 0.35 & 0.00 & 1.00 & 4,005 \\
Difference in Latitude & 0.24 & 0.46 & 0.00 & 2.00 & 4,005 \\
Difference in Longitude & 28.04 & 22.16 & 0.01 & 106.29 & 4,005 \\
\hline Note: There are 900 countries & 65.86 & 53.35 & 0.02 & 284.46 & 4,005 \\
\hline
\end{tabular}

Note: There are 90 countries in our sample, and therefore we have $(90 \times 89) / 2=4,005$ bilateral observations. GDP is measured as Real GDP at constant 2011 national prices in 2011 US Dollars. GDP and population are both for the year 2010 and stem from the Penn World Tables 9.0. Data on Libya are not available in the PWT, and therefore we impute these values using the World Bank World Development Indicators. Relative Differences in WVS are missing for the United States, since they are measured for all other countries relative to the United States. 